\title{
TECNOLOGIAS DIGITAIS, LETRAMENTOS E A COLABORAÇÃO NA FORMAÇÃO DE PROFESSORES
}

\author{
Digital Technologies, Literacies and Collaboration in Teacher Education
}

\author{
Fabrício Tetsuya Parreira ONO, UFRR ${ }^{1}$ \\ Denise Silva Paes LANDIM ${ }^{2}$
}

\begin{abstract}
RESUMO: O artigo buscar compartilhar reflexões acerca da formação de professores em tempos de práticas sociais mediadas pelas tecnologias digitais, que possibilitam não apenas novas formas de ensino e aprendizagem, trabalho, comunicação e relacionamento, mas também apontam para uma condição pós-humana do ser (SANTAELLA 2007). Tais reflexões são fruto de pesquisa realizada com estudantes em uma disciplina de pósgraduação em que se puderam experimentar questões da condição pós-humana em práticas de letramentos (LANKSHEAR e KNOBEL 2011) reveladoras de aprendizagens colaborativas, ubíquas, não-lineares e incertas e que expuseram a questão da diferença na relação com o Outro.
\end{abstract}

PALAVRAS-CHAVE: letramentos; tecnologias digitais; formação de professores; aprendizagem colaborativa.

ABSTRACT: This article aims at sharing thoughts on teacher education in times of social practices mediated by digital technologies, which can afford not only new ways of teaching and learning, work, communication and relationships, but also point to a posthuman condition of being (SANTAELLA 2007). Such thoughts arise from research carried on with graduate students in which issues of the post-human condition in literacies practices (LANKSHEAR; KNOBEL 2011) revealed learnings that were collaborative, ubiquitous, non-linear and uncertain and that showed the topic of difference in the relation with the Other.

KEY WORDS: literacies; digital technologies; teacher education; collaborative learning.

\section{INTRODUÇÃO}

Este artigo busca promover uma reflexão sobre formação de professores por meio de uma perspectiva que contempla as tecnologias digitais tendo como pressuposto a aprendizagem colaborativa (JOHNSTON, 2009) e ubíqua (KALANTZIS e COPE, 2005, 2010) - conceitos a serem discutidos ao longo deste texto. Nesse intento, apresentamos um relato de experiência realizada com participantes de diversas áreas do conhecimento,

\footnotetext{
${ }^{1}$ Professor da UFRR, doutorando em Estudos Linguísticos e Literários em Inglês pela Universidade de São Paulo, com pesquisa focada em formação de professores e os Novos Letramentos, Multiletramentos e Letramento Crítico.

${ }^{2}$ Mestranda em Estudos Linguísticos e Literários em Inglês pela Universidade de São Paulo.
} 
alunos da disciplina de pós-graduação Tecnologias Digitais em Espaços Educativos, na Escola de Comunicação e Artes da Universidade de São Paulo.

Participaram da disciplina 19 (dezenove) mestrandos e doutorandos regularmente matriculados e 5 (cinco) ouvintes. Seis desses participantes colaboraram para este relato, obtido por meio de um questionário online aplicado após o término do curso, no formato Google Docs, contendo três perguntas abertas (anexo 1), com o objetivo de compreender a perspectiva dos participantes a respeito das práticas de colaboração vivenciadas na disciplina.

Apesar de o curso ter sido ministrado no formato tradicional de encontros presenciais semanais, muitas das variadas atividades propostas pela ministrante nos levaram a realizar encontros online, com destaque para o uso das ferramentas do Google Groups e de um grupo secreto no Facebook. Vale ressaltar que ambos os grupos foram cadastrados nas referidas ferramentas de comunicação digital por iniciativa dos próprios estudantes. Além das interações materializadas em coletivo, isto é, acessíveis e discutidas por todos os integrantes da disciplina via e-mails do Google Group e postagens no grupo do Facebook, diversas interações ocorreram em duplas e grupos menores, dependendo das necessidades apresentadas pelas tarefas.

Como as atividades propostas pela ministrante, que partiam da leitura de textos focados em tecnologias digitais e educação, não apontavam sequências lineares e regras a serem seguidas, deu-se margem para que seguíssemos caminhos incertos e renegociáveis a qualquer momento - muitas vezes divididos em subgrupos, ora por área de estudos, ora por afinidade, tanto online quanto offline. Desta forma, nada ficava restrito a certo número de pessoas e não havia um líder, ou seja, nenhuma das atividades propostas pôde ser caracterizada por uma hierarquia vertical, mas sim horizontal. Deste modo, todas as tarefas idealizadas, planejadas e executadas eram compartilhadas, reavaliadas e renegociadas pelo grupo, o que levava a uma constante redefinição de objetivos. Como consequência disso, os caminhos seguidos para atingir as finalidades em comum eram sempre desconhecidos e em grande parte mediados pelas ferramentas digitais, ou seja, inconstantes e repensados sempre que necessário.

Por sua estruturação pautada em um caminho ubíquo e coletivo - conceitos que serão tratados a seguir - a experiência do curso nos levou a refletir sobre as práticas na formação de professores diante das transformações ocorridas no mundo contemporâneo, que exigem de um grupo cada vez maior de pessoas que lidem com incertezas e 
ubiquidades das interações, reorganizando e ressignificando práticas tidas como certas, lineares e verticais.

Diante dessas reorganizações e ressignificações de práticas e eventos que se colocam atualmente, pensamos na busca de alternativas focadas em uma educação que contemple as tecnologias digitais, a colaboração, o ensino crítico e os letramentos. Por isso, dispomo-nos a pensar na formação de professores em tempos em que a tecnologia e a colaboração exercem um papel importante no desenvolvimento profissional e também nas relações humanas de qualquer natureza.

De um modo geral, a nova organização de práticas sociais tem fugido da certeza, da linearidade e da verticalidade, uma vez que vem obedecendo a uma outra lógica, $a$ lógica das redes. Isso é apontado por Castells (2011) como um fenômeno contemporâneo introduzido, junto com a globalização, pelas tecnologias digitais de informação e comunicação, que vêm se ampliando desde o último quarto do século XX. De acordo com o autor, a lógica das redes tem transformado uma série de padrões organizacionais, como os padrões socioculturais, institucionais, econômicos, políticos e até mesmo tecnológicos. Porém, o padrão mais evidentemente afetado por essas transformações é a comunicação, que tem operado sob a regência da multimodalidade e da interatividade.

Seguindo a diversidade de transformações impulsionadas pelo desenvolvimento tecnológico, o ser humano pode também ser compreendido de uma nova maneira, o que Santaella (2007) trata por condição pós-humana. Conforme a autora, as descobertas e desenvolvimentos tecnológicos modificam o pensamento do homem quanto ao seu entendimento da natureza e o do próprio ser humano, caracterizado pelos hibridismos, não apenas no que se refere às relações do humano com a tecnologia, mas também do humano com o inorgânico da natureza. Nesse sentido, entendemos que a emergência de um ser humano caracterizado pela miscigenação e pela hipercomplexidade, cujas relações e interações tendem a seguir caminhos incertos mediados pelas tecnologias digitais, reconfigura seus modos de agir e de pensar.

Com tal reconfiguração nos modos de agir e de pensar, surgem novas formas de aprender e, por consequência, de ensinar. Daí a premência de novas reflexões na formação de professores.

De acordo com as contribuições na área de letramentos promovidas por Kalantzis e Cope (2008), há diferenças importantes entre o ensino e a aprendizagem ocorridos dentro e fora das salas de aula. Segundo os autores, na aprendizagem por design, 
ocorrida dentro de um modelo instrucional e institucional, seus participantes têm papeis definidos. A aprendizagem por design difere, ainda nos estudos de Kalantzis e Cope, da aprendizagem ubíqua. Essa tem se evidenciado singularmente em tempos de crescente influência das tecnologias digitais para a comunicação entre as pessoas, que atuam significativamente em transformações sociais e epistemológicas, ou seja, colaboram para mudanças na construção/produção de conhecimentos.

De acordo com os pressupostos da aprendizagem ubíqua, aprender é construir conhecimento de forma ativa e engajada a um contexto que se expande na esfera pública. Isto porque tanto o processo quanto o produto das aprendizagens ubíquas se tornam material de consulta e constante atualização para que outras pessoas o acessem e, por meio deles, produzam novos conhecimentos. Portanto, o conceito de aprendizagem ubíqua realça a possibilidade de aprendizagem e construção de conhecimentos descentralizados da escola: eles podem ocorrer a qualquer momento, em qualquer lugar, o tempo todo, desenvolvidos por qualquer pessoa (KALANTZIS e COPE 2010)

O fortalecimento da aprendizagem ubíqua pode resultar não apenas em novas relações com o conhecimento, mas também em sua crescente valorização. Cope e Kalantzis (2012) enfatizam ainda que, como efeito da aprendizagem ubíqua, a instituição escolar ganha novo status e posicionamento: cresce a necessidade de formação escolar voltada para a aprendizagem para a vida (lifelong learning), em que o mais importante não é necessariamente $o$ que se aprende, mas como se aprende.

$\mathrm{Na}$ experiência aqui relatada, observamos nossa exposição a práticas de aprendizagens por design e ubíquas. Partindo do pressuposto de que cursamos uma disciplina oferecida por uma universidade estadual, com suas especificidades e regras institucionais, as tarefas por nós executadas sempre eram propostas pela ministrante da disciplina, caracterizando uma certa definição de papeis no design do curso. Entretanto, as tarefas propostas em geral exigiam traduções de conteúdos de suportes tradicionais, como textos impressos e capítulos de livros, para mídias digitais acessíveis a qualquer pessoa na rede, como páginas e apresentações online no formato Flash e vídeos do Youtube, que entendemos como processos e produtos de aprendizagens ubíquas. Durante a execução das tarefas, desenvolvemos uma lógica de rede que nos permitia negociações e renegociações, tanto no que se referia ao papel executado dentro de uma atividade quanto ao caminho percorrido para realizá-la. Além disso, durante as execuções das propostas, que demandavam constantes interações que extrapolavam os encontros 
presenciais semanais, havia abertura para o estabelecimento de outros objetivos que consequentemente levavam a outras tarefas, bem como outros papeis entre os grupos de estudantes.

No que se refere ao coletivo tratado aqui, Latour (2005) aponta que, dentro de uma perspectiva de estudos das sociedades pós-modernas, os grupos resultam de um tumulto constante realizado por inúmeras vozes. Nesse sentido, é possível dizer que as interações e realizações em grupo não podem ser entendidas e planejadas como algo sólido, previsível e silencioso, mas como um composto de todas as vozes que as integram, permeado pelas constantes renegociações de papeis, caracterizado pela horizontalidade. Vale ressaltar que a horizontalidade não exclui a existência de uma hierarquia, que entretanto segue um outro padrão, não mais de cima para baixo ou vice- versa, mas centrado no objetivo comum de realização das tarefas propostas, exigindo-se decisões conjuntas, tomadas pelo grupo a partir das discussões, característica saliente nas experiências que vivenciamos durante a execução das atividades da disciplina.

O trabalho em grupo, numa perspectiva pós-humana e pós-moderna (LATOUR, 2005; SANTAELLA, 2007), segue uma dinâmica não previsível, não linear e cria desestabilizações para aqueles participantes que têm o hábito de seguir regras e movimentos lineares para atingir determinados objetivos propostos pelo curso em questão. Para Latour (2005), essas desestabilizações são vistas como redefinições de tarefas a partir das relações dos seus atores - aqueles que compõem o grupo. Desta forma, os grupos podiam redefinir suas tarefas, por meio das ações e caminhos apontados pelos participantes, a qualquer momento, conforme as necessidades e (re)negociações durante a execução de determinadas tarefas para as quais não nos sentíamos preparados no início do curso, o que gerou desconforto em quase todos os participantes.

Dada a complexidade constitutiva do trabalho em grupo, corremos o risco do isolamento ou aproximação apenas de pessoas e ideias que se assemelham às nossas como forma de manutenção de uma zona de conforto. Portanto, se o mundo de hoje exige que o ser humano se compreenda como miscigenado e hipercomplexo, podemos pensar na formação de professores que evite o isolamento e a busca pelas semelhanças? $\mathrm{Ou}$, ainda, podemos pensar na formação de professores que se distancie da perspectiva de "treinamento", no sentido de alinhar ideias ao conformá-las a planejamentos uniformes, estáveis e, portanto, controláveis? 
Acreditamos, após a experiência na disciplina, que um dos caminhos que contemplam as demandas das relações humanas nas sociedades contemporâneas possa ser a colaboração, que se tornou elemento essencial para os docentes saírem do isolamento profissional, conforme pontua Johnston (2009). Para o autor, a formação de professores deve ser um processo fundamentalmente colaborativo. Também, entendemos ser viável repensar os planos de trabalho na formação de professores tendo em vista a colaboração entre os participantes como um eixo norteador das práticas de sala de aula, por meio de planejamento prévio, na escolha das atividades propostas considerando as especificidades de cada contexto. Espera-se, assim, que o desenvolvimento colaborativo de professores seja uma prática comum encontrada em uma variedade de contextos em oposição à perspectiva de treinamento ofertada a professores, não raro percebidos como trabalhadores cujo desenvolvimento profissional acontece de forma individual e restrita à sala de aula.

A formação de professores com vistas à colaboração expande a visão de ensino e aprendizagem como um processo social, conforme os estudos de letramentos desenvolvidos por Lankshear e Knobel (2011). Ainda nos termos de Lankshear e Knobel, entende-se que o ensino e aprendizagem sociais comportam a visão de conhecimento como produção de seus participantes em realizações sociais, superando, dessa forma, um ideário cartesiano de educação (LANKSHEAR e KNOBEL 2011, p. 218). Na perspectiva dos letramentos, os educadores, tanto individualmente quanto em comunidade, são agentes de produção e não apenas consumidores de conhecimento e compreensão sobre o ensino, o que vai ao encontro do que Monte Mór (2006, p. 349) entende como necessidade de se buscar "novos dados para as reflexões e reinterpretações sobre o quadro que reiteradamente vem sendo analisado no ensino de línguas estrangeiras".

Johnston (2009), por usa vez, também nos faz saber que o desenvolvimento colaborativo de professores pode ser qualquer investigação sustentada e sistemática em ensino e aprendizagem na qual um(a) professor(a) colabora voluntariamente com outros envolvidos no processo, tendo como fim o desenvolvimento profissional. Desta forma, ele sugere quatro possibilidades, a primeira delas é que professores poderiam colaboram com seus colegas; a segunda propõe a colaboração entre professores e universidades; a terceira, a colaboração de professores e alunos; e também, a colaboração de professores com outras pessoas envolvidas no processo educacional. 
A partir das possibilidades elencadas por Johnston, focamos na colaboração entre professores retomando a necessidade de entendermos que essas colaborações não sejam vistas como interações estáveis, providas de certezas e hierarquicamente verticais.

Diante desse panorama teórico, apresentaremos a seguir dados extraídos do questionário enviado aos participantes da disciplina no qual buscamos compreender o papel da colaboração em suas práticas de aprendizagem. Os dados apontaram para incertezas e ubiquidades inerentes às interações sob as quais se construíram tais aprendizagens, reforçando-as, a partir de uma perspectiva de letramentos, como práticas sociais ocorridas em contex to (LANKSHEAR e KNOBEL, 2011). Assim, analisamos os comentários de participantes que mais nos esclareceram sobre o movimento de incerteza e ubiquidade envolvidos em suas práticas de aprendizagem. Cada comentário está identificado por seus autores, denominados P1, P2 e assim por diante.

\section{A INCERTEZA DO EU E DO OUTRO}

Um dos aspectos que mais se ressaltou nas contribuições dos participantes do curso quanto à aprendizagem colaborativa refere-se à existência do outro. A posição deste outro tende a colocar-se, por um lado, como um elemento de incômodo. Por outro lado, dentre as atribuições do outro está o importante papel de avaliar, enriquecer e, especialmente, ajudar a construir a si próprio.

A noção de alteridade como constitutiva de si já foi examinada por diversos estudiosos. Partimos, aqui, do pensamento de Freire (2005) a respeito do outro: o conhecimento de nós mesmos não ocorre em nós, mas a partir do outro. Nessa perspectiva, Menezes de Souza (2011) expande o ensinamento de Freire ao realçar que é tarefa do letramento crítico desenvolver a percepção das relações entre "eu" e o "não-eu" que nos constituem. Para isso, parte-se da necessária tarefa de ouvir esse outro e assim cultivar uma conscientização crítica a respeito do mundo, seus valores e seus significados, que derivam justamente da coletividade em que nos inserimos.

Esse reconhecimento da coletividade e da diversidade contextual em que nos inserimos é mencionado por P1, cujo comentário se reproduz abaixo:

Me chamou a atenção a conscientização do modo como eu trabalho e "funciono" nesse contexto, bem como a diversidade de perfis, habilidades, conhecimentos e competências que se complementam no alcance de um objetivo comum. Lidar com as diferenças e transformar as partes em um todo foi o grande desafio para mim, seja sob a perspectiva de aluna, seja sob a de docente. (P1 - grifos nossos) 
Seguindo o comentário de P1, tal reconhecimento facilitou o conhecimento de si própria no que diz respeito ao modo como aprende e trabalha em relação ao grupo. A participante também reconhece a heterogeneidade sob dois aspectos. $\mathrm{O}$ primeiro aspecto reside nas diferenças nos chamados "perfis" dos integrantes, que entendemos como determinadas diferenças pessoais entre os participantes realçadas nas interações ocorridas nas práticas de aprendizagem da disciplina. Isso nos chama a atenção para o aspecto humano que deve ser considerado nas práticas de aprendizagem colaborativa. $\mathrm{O}$ desafio que reside na complexidade de se lidar com as diferenças pessoais é também mencionado por P2, como se vê no trecho a seguir:

Pude aprender mais com meus colegas da educação [...] Entre os egos e competências as propostas sempre ficavam mais refinadas. ( $\mathrm{P} 2$ - grifo nosso)

Vê-se, no uso do termo "egos", uma questão de cunho individual, que se alinha com a menção de $\mathrm{P} 1$ no que diz respeito às diferenças pessoais que permeiam toda relação humana.

O segundo aspecto levantado no comentário de P1 é a diferença epistemológica, isto é, de conhecimentos mobilizados pelos integrantes. Tais menções nos levam à percepção de que não se trata apenas de saberes isolados por si só, mas de uma relação entre os conhecimentos e as pessoas que os mobilizam. Assim, tais conhecimentos são construídos em suas trajetórias na vida, nas formas como aprendem para dar conta de suas atividades cotidianas, escolares, profissionais, etc. Essa diferença em relação ao eu e o outro, materializada na mencionada heterogeneidade pessoal e epistemológica do grupo, teve que ser tratada nas diversas interações exigidas para a realização de tarefas, conforme apontam P1 e P2, devido à necessidade de objetivos comuns, isto é, estabelecidos pelo grupo e mediados pela ministrante do curso. Ainda que com o intuito de alcançar os ditos objetivos comuns, o trato das diferenças não foi percebido como uma tarefa fácil, mas foi apontada por P1 como um desafio, uma realização complexa.

Ainda com relação às diferenças entre o eu e o outro, a fala de P3 nos traz percepções que acentuam seu caráter provocador e conflituoso, como se observa no trecho abaixo:

O que mais me surpreendeu foi perceber que, em meio ao aparente caos do confronto de ideias e competências de profissionais de distintas áreas, edificavam-se conteúdos e conceitos coerentes, sólidos, abrangentes. (P3, grifo nosso) 
Acerca desse reconhecimento, percebe-se na fala de P3 que lidar com o outro não se trata de algo necessariamente harmonioso. P3 chama de "caos do confronto" o encontro de heterogeneidades de conhecimentos pertencentes a diferentes pessoas - caos que se concretiza e se dilui inúmeras vezes. Em um primeiro momento, P3 pode estar se referindo às diferenças entre essas pessoas por pertencerem a distintas áreas de conhecimento, de profissão, de localização. Em uma perspectiva mais ampla, tais distinções podem ser percebidas como diferentes contextos ou coletividades em que os indivíduos se inserem.

A partir desse excerto, reforça-se o conflito que constitui, de forma geral, qualquer grupo de pessoas já mencionado em Latour. Para o autor, as relações do grupo são "resultados provisórios de um constante tumulto formado por milhões de vozes" (LATOUR, 2005, p.31).

Além do conflito inerente às relações dos grupos, percebemos em P3 uma segunda noção de conflito, advinda de uma suposta tentativa de demarcação de limites entre contextos (limites, áreas de conhecimento, profissões, compreensões de mundo) que é pressuposta no conceito de fronteiras conforme exposto por Buzato (2012). Segundo o autor, se há demarcação de limites entre contextos, pode haver conflito no encontro desses contextos, que são por sua vez heterogêneos. A seguir, o autor elucida que ao mesmo tempo em que há conflito, no espaço da fronteira também há possibilidade de contaminação entre contextos e um consequente alargamento de possibilidades e significados. Assim interpretamos esse "caos do confronto": um espaço em que se edificam “conteúdos e conceitos coerentes, sólidos, abrangentes”, conforme P3.

É nessa compreensão de fronteiras que podemos posicionar o fenômeno da transdisciplinaridade, que é ressaltada por P3 em confronto com a multidisciplinaridade, conforme se observa no trecho abaixo:

\footnotetext{
A definição de aprendizagem colaborativa, após a disciplina, passou a ser o processo de construção de um todo coletivo, a partir a interseção (e não mais soma) de competências e habilidades, de forma transdisciplinar (e não multidisciplinar). (P3 grifos nossos)
}

A esse respeito, Fiorin (2008) nos informa que a transdisciplinaridade tem sido estudada como um fenômeno linguístico, já que a linguagem é heterogênea dada a heterogeneidade das pessoas que dela fazem uso. Expõe que o fazer científico parece ter sido construído por dois princípios: o da exclusão (triagem) e o da participação (mistura). No fazer científico regido pela exclusão, o operador é a triagem: a partir da comparação 
entre determinados objetos, surgem conclusões a respeito do que pertence e ao que não pertence a um grupo. Em outras palavras, surgem conclusões sobre o exclusivo e o excluído, o puro e o impuro. Por outro lado, o fazer científico de participação, cujo operador é a mistura, preconiza comparações entre o igual e o desigual. Isso leva a pensar a igualdade como um valor que permite trocas e intercâmbios, enquanto a desigualdade implica valores que se opõem, como inferior e superior. Em resumo, o princípio da exclusão tende a interditar a circulação de objetos, métodos e conceitos, ao passo que o princípio da participação permite o "comércio" de objetos, métodos, conceitos, etc. (FIORIN 2008, p. 32).

Até meados do século XVII, embora houvesse distinção de áreas de conhecimento que remonta aos gregos, predominou o fazer científico presidido pelo princípio da participação (mistura). Isso se observa, por exemplo, na dificuldade de distinção entre química e alquimia. Essa prática começa a mudar a partir do século XVIII, quando se inicia um movimento de especialização de disciplinas, impedindo que seus objetos, métodos e conceitos circulem e sejam "contaminados" por outras intervenções.

O movimento de especialização de disciplinas - e de seus objetos, métodos e conceitos - passa por novas alterações com a pós-modernidade, que traz consigo as implicações do pós-humano e da hipercomplexidade apontados por Santaella (2007), especialmente no que se refere à retomada do princípio de participação operado por mistura de objetos, métodos e conceitos. Dessa forma, Fiorin (2008) destaca três conceitos que se tornaram recorrentes no fazer científico na pós-modernidade, em que se observa o princípio de participação: a multi ou pluridisciplinaridade, a interdisciplinaridade e a transdisciplinaridade. Para iluminar as distinções entre os termos, o autor recorre à etimologia. Os prefixos multi- e pluri- indicam abundância qualitativa ou quantitativa. Assim, o fazer científico regido por multi ou pluridisciplinaridade pressupõe que várias disciplinas analisem um dado objeto, sem que haja ligação necessária entre essas abordagens disciplinares. Esse fazer ocorre paralelamente, o que resultará, ao final, em uma soma de visões sobre esse objeto. Como inter- significa "dentro", "entre", entende-se que a interdisciplinaridade pressupõe uma convergência, que de um lado permite transferir conceitos de uma disciplina para outra ${ }^{3}$. Já o prefixo trans- quer dizer travessia, deslocamento. De acordo com Fiorin, a transdisciplinaridade

\footnotetext{
${ }^{3}$ Fiorin cita a utilização, por parte do sociólogo Pierre Bourdieu, de conceitos da economia em estudos sobre atividades sociais, que culminaram em conceitos como, por exemplo, capital simbólico.
} 
ocorre "quando as fronteiras das disciplinas se tornam móveis e fluídas num permeável processo de fusão. [...] Da mesma forma, a transdisciplinaridade é domínio da audácia, que leva a examinar todo o conhecimento.” (FIORIN 2008, p.38)

Isso posto, compreendemos a defesa, por parte de Pennycook (2006), da indisciplinaridade da linguística, de modo a torná-la transgressiva, uma vez que "as disciplinas não são estáticas, domínios demarcados de conhecimento aos quais pedimos emprestados construtos teóricos, mas são elas mesmas domínios dinâmicos de conhecimento" (PENNYCOOK 2006, p. 72). Nesse sentido, o autor busca romper com a linguística tradicional, que surge enviesada pelo fazer científico regido pela triagem, em que se busca isolar seu objeto de estudo, a linguagem, por meio de sua compreensão como sendo um sistema universal que precede seu contexto. A linguística transgressiva defendida pelo autor se baseia na transgressão de fronteiras de pensamento, de disciplinaridade, como um aparato político e epistemológico para procurar pensar o que não deveria ser pensado, fazer o que não deveria ser feito. Busca atravessar fronteiras e quebrar regras.

Retornando ao caso aqui relatado, observa-se, por um lado, que a multidisciplinaridade e a interdisciplinaridade orientam a construção de conhecimentos por parte de um grupo heterogêneo de pessoas no sentido de convergir suas áreas de atuação e ideias de maneira isolada, por outro lado a transdisciplinaridade norteia uma tradução (ou transposição, deslocamento) de áreas do conhecimento e pontos de vista divergentes para uma linguagem em comum, em face de determinado problema. Essa tradução, ou transposição, exigiu a transgressão de regras pré-estabelecidas pelos moldes de uma educação convencional e linear.

Tais convenções e linearidades encontram dificuldades de posicionamento nos contextos de construção de saberes e aprendizagens fluídos e colaborativos, emergentes da pós-modernidade, do pós-humano e da hipercomplexidade que agora se realçam pelos conhecimentos difundidos na lógica da mente em rede, como elucida Castells (2011). O conceito de mente em rede é utilizado pelo autor para confrontar a mente tipográfica, formatada pela cultura alfabética predominante até meados do século XX e que vem dando lugar a outras formas de organização social, cultural, econômica e política que advêm, conforme já mencionado, das tecnologias digitais e da globalização.

Conforme se pode observar nas falas dos participantes, a utilização da divergência (não da convergência) tornou-se um fator agregador que favoreceu a solução de 
problemas variados, o que não foi tarefa fácil. O caminho compreendido para a utilização das opiniões divergentes é sinalizado por P4, quando realça dois fatores importantes para a ocorrência da colaboração: (1) o respeito à diferenças conforme observadas na individualidade diante do coletivo; (2) a humildade e a generosidade na execução das tarefas. Segue o trecho em que P4 aponta para esse caminho:

\begin{abstract}
O trabalho colaborativo a meu ver é aquele onde todos constroem juntos um aprendizado a partir da troca, onde são somadas diferentes habilidades de forma coesa, respeitando-se o individual dentro do coletivo e o vice-versa. Não diria que houve quebra de paradigma, mas que a maturidade intelectual de todos os membros do curso colaborou para que as trocas fossem mais ricas e produtivas, onde a humildade e generosidade de todos foi fator facilitador desta construção. (P4 - grifos nossos)
\end{abstract}

A humildade e a generosidade mencionada por P4 aproximam-se do conceito de pensamento fraco, utilizado por Vattimo e Zabala (2011) para designar epistemologias surgidas no contexto da pós-modernidade, em que se questionam conceitos metafísicos fundadores da modernidade, tais como verdade, homem, ciência, razão, território, etc. Com trabalhos seminais como os de Nietzsche, Heidegger e Derrida, o aclamado fim das metafísicas é o contexto em que os autores dizem ser possível desenvolver o pensamento fraco. Para conceituar pensamento fraco, os autores partem da defesa de Rorty de que o conhecimento não pode ser obtido com base na decisão metafísica sobre a verdade, mas com base na conversa. Eles ressaltam que a conversa pressupõe uma comunidade epistemológica, um contexto, uma prática e, a depender do empenho em ajustar circunstâncias para alcançar cooperativamente os objetivos colocados pelas pessoas que atuam nessa comunidade, gera-se a humildade que subjaz o respeito e a tolerância pelo pensamento do outro (VATTIMO e ZABALA 2011, p.105-106).

\title{
O CONTROLE E A SUSPENSÃO DOS SABERES
}

Ao se enfatizar o contexto, lembremos de que toda prática social é situada. A aprendizagem colaborativa, nosso interesse neste texto, sendo uma prática social, localiza-se em um contexto, em um tempo e em um espaço que são construídos e que constroem suas possibilidades (affordances). Essa relação entre o contexto/local da aprendizagem é observada por P5, ao mencionar a diferença entre o espaço físico da sala de aula e o espaço interativo online que foi estabelecido para a realização de tarefas, conforme o trecho abaixo: 
[Conjunto de atividades colaborativas à distância]Difere de atividades colaborativas na sala de aula em que os rumos da discussão podem ser definidos no "aqui" e no "agora" e podem ser renegociados o tempo todo sem que isso demande esforços maiores (como a redação ad infinitum de mensagens de e-mail). Por outro lado, importante perceber que a liberdade de ação abre espaço para que se destaque a postura proativa de alguns colegas que assumiram de corpo e alma o trabalho. (P5, grifos nossos)

P5 confronta negociações e construções de sentido em aula e em pós-aula, nos ambientes virtuais. É evidente que em ambos os contextos, presencialmente ou online, a divergência de ideias foi acentuada e, de diversas maneiras, prevista e até mesmo incentivada em nosso grupo. Vale ressaltar que, embora em certos grupos possam existir tentativas de apagamento de divergências, as divergências caracterizam qualquer grupo, dada a sua heterogeneidade, conforme aponta Latour (2005). O que nos parece interessante na colocação de P5 é, de fato, a dificuldade de (re)negociação em ambientes online, justamente por sua fluidez e por escaparem às orientações do professor, das paredes da sala de aula e dos muros da instituição escolar. Essa configuração da sala de aula, embora o caso aqui relatado seja o de um grupo de estudantes que foi estimulado a agir de forma inovadora, recupera e muito a tradição das posições de ambientes educacionais, o que é esperado, como já se mencionou em Cope e Kalantzis (2008) em sua elucidação sobre a aprendizagem por design. O que nos parece ter causado desconforto a P5 diante da fluidez das interações online é justamente sua concepção de que o controle de papeis deva também fazer parte nas interações online para fins educacionais. É o que se apreende do trecho a seguir:

\footnotetext{
Acho essencial que em atividades colaborativas a distância cada um se responsabilize por uma ação, defina claramente os objetivos que pretende alcançar para contribuir com o grupo e saiba as próximas etapas (e para onde elas conduzem). (P5 - grifos nossos)
}

Ainda assim, em uma concepção mais fluída de aprendizagem que comporta a ubiquidade e a transposição de barreiras, conforme a defesa dos estudiosos de letramentos, aprender envolve essa lida com o outro em toda a sua heterogeneidade, e que, por sua vez deve se tornar uma negociação em aberto. De uma perspectiva pósmoderna derridiana, Biesta (2009) já nos pontua que a educação, sendo um ato de comunicação, corre o risco de problemas de interpretação e mal-entendidos. Assim, mesmo que se tenha a criticada perspectiva de "transmissão de conhecimentos" das pedagogias tradicionais que se baseiam em modelos de comunicação caracterizados por interações unilateriais entre o professor transmissor e o aluno receptor, a compreensão da 
mensagem só pode ser efetiva dependendo do trabalho de interpretação dos alunos. Do ponto de vista dos estudos de letramentos, as interações pedagógicas são ainda menos passíveis de controle e regulação, como se depreende, no caso aqui analisado, dos atos de comunicação e negociação entre alunos em suas aprendizagens.

De acordo com Biesta (2009), Derrida considera a educação dessa maneira porque cada ato de fala considerado bem sucedido é uma imagem idealizada, já que depende de um rígido controle das condições e das interpretações dos supostos receptores da mensagem transmitida, como no ambiente educacional que pressupõe papeis claros e definidos. Portanto, em um contexto em que não se pressupõe esse excessivo controle, cada ato de fala é imprevisível, e o risco de falha de comunicação é inerente a ele. Do contrário, o ato de fala seria mecânico e sem significado. A interação e a comunicação humana são eventos, não mecanismos. Se retirássemos o risco envolvido na comunicação, também removeríamos a oportunidade do outro ser o outro.

Dessa maneira, o gap entre ensino e aprendizagem é fechado em processos de avaliação - não como o resultado bem sucedido da transmissão de conhecimentos do professor para o aluno, mas o efeito de uma intervenção normativa específica nos modos como os alunos respondem e constroem significados sobre o que eles estão sendo ensinados (BIESTA 2009).

Face a essa abertura para o outro e todas as dificuldades de comunicação e construção de conhecimentos que isso ocasiona, torna-se valiosa a ideia de aprender a aprender para a incerteza, tal qual salienta Morin (2010). Ao discorrer sobre os limites do conhecimento, Morin (2010, p.55) salienta a indestrutibilidade das incertezas tanto nas ações quanto no conhecimento, o que é tratado como um grande avanço para a humanidade.

É nesse sentido que podermos compreender o que P6 aponta como o que mais the marcou durante a experiência de aprendizagem colaborativa, conforme se observa no trecho abaixo:

O que mais me marcou foi o tempo de suspensão dos saberes, o tempo do não saber o que irá emergir, de ser preciso esperar os outros, o grupo para descobrir o que será criado em conjunto. (P6 - grifos nossos)

Justamente por trabalhar em grupo, por si só caótico, que necessitava trabalhar junto por seus objetivos comuns é que P6 parece ter experimentado a suspensão de saberes e a certeza da incerteza (MORIN 2010). É o que nos parece fazer sentido se pensarmos nas constantes mudanças que são inerentes à vida social e que têm se tornado 
evidentes em tempos de globalização e pós-modernidade: evidenciam-se a diferença e o questionamento de conceitos que antes eram considerados absolutos e universais.

Nesse sentido, nos parece importante realçar que o controle, a rigidez e a organização fragmentária de saberes e verdades, que por séculos nos conduziram e nos "formataram" em determinadas ações como educadores, têm dado lugar a saberes cada vez mais ubíquos, fluídos, incertos e coletivos. Tais saberes não são privilégio das interações online, mas se tornam cada vez mais perceptíveis em todo tipo de prática social.

\section{AINDA PRECISAMOS...}

O que se entende aqui não é a colaboração como apaziguadora das diferenças individuais e epistemológicas dos indivíduos participantes, mas uma (des)estrutura horizontal, não linear, que proporciona aos envolvidos a oportunidade de perceber, demonstrar, ressaltar seus valores, conhecimentos e não saberes perante um grupo, refinando sua postura e participação em movimentos e em momentos nos quais um só elemento não pode chegar ao fim sem passar pelo coletivo/colaborativo. Além disso, salientamos o dinamismo das interações, que não percorrem vias lineares, nem unidirecionais - do indivíduo para o todo ou vice-versa, uma vez que as tecnologias digitais corroboram eventos que se realizam da forma mencionada anteriormente aqui.

Entendemos, também, que experiências colaborativas de aprendizagem subsidiam-se no que Sousa Santos (2010) intitula Ecologia dos Saberes ao discutir a linha/fronteira/barreira invisível que separa os indivíduos. Ou seja, aquilo que não vemos, não existe. Essas linhas que nos separam são tão comuns que, muitos de nós, nem percebemos que elas estão aí, ali e acolá. O pensamento abissal não aceita a coexistência, a copresença e, desta forma, fundamenta os conflitos da vida moderna.

Por isso entendemos que ainda é preciso mais investigações no campo da formação de professores de línguas no que se refere ao uso de tecnologias e colaboração, que hoje percorre um caminho coletivo, ubíquo e incerto. 


\section{REFERÊNCIAS}

BIESTA, G. From critique to deconstruction: Derrida as a critical philosopher. In: PETERS, M.; BIESTA, G. Derrida, Deconstruction and the Politics of Pedagogy. Peter Lang: New York, 2009.

BUZATO, M. Letramentos em rede: textos, máquinas, sujeitos e saberes em translação. In: Revista Brasileira de Linguística Aplicada. Belo Horizonte, v. 12, n. 4, p. 783-809, 2012.

CASTELLS, M. A sociedade em rede - A era da informação: economia, sociedade e cultura; v.I). São Paulo: Paz e Terra, 2011.

FIORIN, J.L. Linguagem e interdisciplinaridade. In: Alea, Rio de Janeiro, v. 10, n. 1, Junho 2008 . Disponível em <http://www.scielo.br/scielo.php? script=sci_arttext\&pid $=\mathrm{S} 1517-106 \mathrm{X} 2008000100003 \& \operatorname{lng}=\mathrm{en} \& \mathrm{nrm}=\mathrm{iso}>$. Acesso 13 de maio de 2013 .

JOHNSTON, B. Collaborative Teacher Development. In: BURNS, A.; RICHARDS, J.C. Cambridge Guide to Second Language Teacher Education. Cambridge: CUP, 2009.

KALANTZIS, M; COPE, B. New Learning: Elements of a science of education. Cambridge University Press, 2008.

KALANTZIS, M.; COPE, B. Ubiquitous Learning. Exploring the anywhere/anytime possibilities for learning in the age of digital media. University of Illinois Press, 2009, 264 pp.

KALANTZIS, M.; COPE, B. (eds.) Ubiquitous Learning. Urbana and Chicago: University of Illinois Press, 2010.

KALANTZIS, M; COPE, B. Literacies. New York: Cambridge University Press, 2012.

LATOUR, B. Reassembling the social: an introduction to actor-network-theory. New York: Oxford University Press, 2005.

LANKSHEAR, C.; KNOBEL, M. New Literacies: Everyday Practices and Social Learning. Berkshire, England: Open University Press Mc Graw-Hill Education, 2011.

MENEZES DE SOUZA, L. M. T. Para uma redefinição de Letramento Crítico: conflito e produção de significação. In: MACIEL, R.F \& ARAÚJO, V.A. (orgs). Formação de Professores de Línguas: ampliando perspectivas. São Paulo: Paco Editorial, 2011. pp.128-140.

MONTE MÓR, W. A Mediação entre a Teoria e a Prática no Ensino de Línguas Estrangeiras. In: Revista Crop, v. 11. São Paulo: Editora Humanitas, 2006.

MORIN, Edgar. A cabeça bem-feita: repensar a reforma, reformar o pensamento. Rio de Janeiro: Bertrand Brasil, 2010.

PENNYCOOK, A. Uma linguística aplicada transgressiva. In: MOITA LOPES, L. P. (org.) Por uma linguística aplicada indisciplinar. São Paulo: Parábola, 2006.

. Critical and alternative directions in applied linguistics. Australian Review

of Applied Linguistics 33 (2), 16.1-16.16. DOI: 10.2104/aral1016. University Press, 2010.

SANTAELLA, L. Linguagens líquidas na era da modernidade. São Paulo: Paulus, 2007.

SOUSA SANTOS, B; MENESES, M.P. (orgs.) Epistemologias do Sul. São Paulo: Cortez, 2010.

VATIMMO, G. ZABALA, S. Hermeneutic Communism: From Heidegger to Marx. New York: Columbia University Press, 2011. 


\section{ANEXO 1 : Perguntas do questionário}

1) Qual é a sua formação e atuação profissional?

2) A partir das experiências vivenciadas durante a disciplina, como você interpreta o conceito de aprendizagem colaborativa hoje? Houve quebra de paradigma durante o curso?

3) Você pode mencionar, a partir do seu ponto de vista, o que mais lhe chamou a atenção durante a execução dos trabalhos colaborativos realizados durante a disciplina? 